\title{
Aneuploidy is permissive for hepatocyte-like cell differentiation from human induced pluripotent stem cells
}

\author{
Fallon K Noto ${ }^{\dagger}$, Megan R Determan ${ }^{\dagger}$, Jun Cai, Max A Cayo, Sunil K Mallanna and Stephen A Duncan ${ }^{*}$
}

\begin{abstract}
Background: The characterization of induced pluripotent stem cells (iPSCs) and embryonic stem cells (ESCs) routinely includes analyses of chromosomal integrity. The belief is that pluripotent stem cells best suited to the generation of differentiated derivatives should display a euploid karyotype; although, this does not appear to have been formally tested. While aneuploidy is commonly associated with cell transformation, several types of somatic cells, including hepatocytes, are frequently aneuploid and variation in chromosomal content does not contribute to a transformed phenotype. This insight has led to the proposal that dynamic changes in the chromosomal environment may be important to establish genetic diversity within the hepatocyte population and such diversity may facilitate an adaptive response by the liver to various insults. Such a positive contribution of aneuploidy to liver function raises the possibility that, in contrast to existing dogma, aneuploid iPSCs may be capable of generating hepatocyte-like cells that display hepatic activities.
\end{abstract}

Results: We examined whether a human iPSC line that had multiple chromosomal aberrations was competent to differentiate into hepatocytes and found that loss of normal chromosomal content had little impact on the production of hepatocyte-like cells from iPSCs.

Conclusions: $\mathrm{PSC}$ s that harbor an abnormal chromosomal content retain the capacity to generate hepatocyte-like cells with high efficiency.

Keywords: iPSC, Hepatocyte differentiation, Aneuploidy

\section{Background}

The availability of human pluripotent stem cells has provided a cell culture platform for study of human disease and development [1]. Pluripotent cells could also potentially be used therapeutically as a source of cells for transplant or drug discovery. Moreover, the finding that patient-specific pluripotent cells can be relatively easily generated by molecular reprogramming raises the prospect of using personalized regenerative medicine to treat a variety of diseases, arguably without fear of immune rejection $[2,3]$. While the biomedical potential of pluripotent stem cells is irrefutable, to realize such potential requires an in depth understanding of the

\footnotetext{
*Correspondence: duncans@mcw.edu

${ }^{\dagger}$ Equal contributors

Department of Cell Biology, Neurobiology and Anatomy, The Medical

College of Wisconsin, 8701 Watertown Plank Road, Milwaukee, WI 53226, USA
}



(c) 2014 Noto et al.; licensee BioMed Central Ltd. This is an Open Access article distributed under the terms of the Creative Commons Attribution License (http://creativecommons.org/licenses/by/2.0), which permits unrestricted use, distribution, and reproduction in any medium, provided the original work is properly credited. The Creative Commons Public Domain Dedication waiver (http://creativecommons.org/publicdomain/zero/1.0/) applies to the data made available in this article unless otherwise stated. fundamental properties and complications that are associated with genomic changes that accompany the reprogramming process. Many studies have revealed that, as a consequence of reprogramming and stem cell culture, genetic instability commonly occurs [4]. The genetic variations that have been observed are diverse and include copy number variations (CNVs), chromosomal rearrangements, and several sub-chromosomal mutations including deletions and point mutations [5-10]. For pluripotent cells to be used safely in regenerative medicine, substantial characterization would therefore be necessary to ensure the genomic integrity of transplantable cells.

Although it is clear that iPSC-derived cells used for cell therapy should be euploid due to the need for safety, how chromosomal variation affects the production of differentiated cells in culture remains ill defined. Cell differentiation is an orchestrated process that relies on 
complex extracellular signals coupled with epigenetic and genetic responses, which establish transcription factor networks that drive cell fate. With this in mind it would seem intuitive that aneuploid genomes would be detrimental to the differentiation of a specific cell type. However, analyses in both mice and humans have shown that, unlike most somatic cells, the chromosomal content of proliferating hepatocytes is diverse and that aneuploidy is commonly observed $[11,12]$. In liver damage models it has been established that changes in chromosomal content are dynamic with cells constantly gaining and losing chromosomes. This dynamic nature of chromosomal imbalances found in hepatocytes has been referred to as the 'ploidy conveyer' and it has been hypothesized that the conveyer may facilitate an adaptive response of hepatocytes to noxious environments [11]. With this model in mind, it is formally possible that hepatic function may best be recapitulated if hepatocytes are generated from iPSCs that display genomic variation. The generation of polyploidy in rodent hepatocytes begins after weaning and increases as the animals age; however, the impact of aneuploidy on hepatocyte differentiation is unknown. We, therefore, addressed whether hepatocytelike cells could be generated from iPSCs that are karyotypically abnormal.

\section{Results}

\section{Characterization of aneuploid iPSCs}

We have previously described the generation of a human iPSC line, referred to as iPSC-K3, which was produced by reprogramming foreskin fibroblasts using transient transfection of plasmids that express OCT4, NANOG, LIN28, and KLF4 [13]. These iPSCs are free of integrated exogenous DNA and have a high capacity to differentiate into cells that display characteristics of hepatocytes. The iPSC-K3 cells maintain a stable karyotype; however, as with all human pluripotent stem cells, colonies spontaneously arise that contain chromosomal variations that presumably support their efficient proliferation in culture [4].

During routine analyses of a subculture of iPSC-K3 cells we identified a cell line that was extensively aneuploid (Figure 1 and Table 1). In this culture, the majority of the cells approached a tetraploid state, but included both gain and loss of discrete chromosomes as well as chromosomal rearrangements. The composite karyotype of the line, determined by examination of 19 cells with consistent abnormalities, is XXYY,-3[19],-6[18],-7[5],-8 [18],-11[16],+12[19],-13[3],-14[4],-15[19],-16[12],-17[5], $\operatorname{dup}(17)(q 11.2 q 25)$ ins(17)(q25;q25q11.2)[19],-18[12],-19 [19],-22[11]. These 19 cells contained 79 87 chromosomes per cell and the frequency of a given chromosomal imbalance is indicated within the square brackets ([n]). The major chromosomal imbalances observed were a gain of chromosome 12 and loss of chromosomes $3,6,7,8,11$, $13,14,15,16,17,18,19$ and 22 . In addition, in all 19 cells we observed an unbalanced structural abnormality of chromosome 17 that represented a gain of long (q) sequences from chromosome 17 (dup(17)(q11.2q25)ins(17) (q25;q25q11.2)). Rearrangements of chromosome 17 have been commonly found in both human ESCs and iPSCs and are believed to confer advantageous growth in culture [8]. Although all cells examined were abnormal not all cells contained every observed rearrangement. Chromosomal imbalances found in a minority of cells included loss of chromosomes $7,13,14,18$, and 22 , raising the possibility that the culture arose from a mixed population. However, given that all cells approached tetraploidy, we favor an alternative explanation in which the cells originated clonally from a single tetraploid event and subsequently diverged in culture. Figure 1 shows karyograms of the parental iPSC$\mathrm{K} 3$ line and a single cell from the aneuploid iPSC-K3 (iPSC-K $3^{\text {aneuploid }}$ ) derivative that contains the majority of the chromosomal abnormalities that were identified and Table 1 describes the frequency of each abnormality. In addition to the majority of the cells that displayed a shared karyotype, a single non-clonal cell was identified with the karyotype $66, \mathrm{XXY},+1,+2,-3,+4,+5,+9+12,-14,-15,-16$, dup (17)(q11.2q25)ins(17)(q25;q25q11.2),-19,-19,-21,-21,-22.

Despite the abnormal karyotype, the iPSC-K3 $3^{\text {aneuploid }}$ cells formed colonies that displayed a morphology that is characteristic of human pluripotent stem cells and immunocytochemistry revealed that the majority of cells within the colonies expressed the pluripotency marker OCT4 (Figure 1C). In addition, FACS analyses revealed that close to all of the cells in the culture expressed the pluripotent cell surface markers SSEA-4 (99\%) and Tra-1-81 (96\%), but not the fibroblast marker CD13 (Figure 1D).

\section{Differentiation of iPSC-K3 $3^{\text {aneuploid }}$ cells to hepatocyte-like cells}

To determine whether iPSCs harboring chromosomal variation could form hepatocyte-like cells in culture, we subjected iPSC-K3 $3^{\text {aneuploid }}$ cells to culture conditions that we have previously demonstrated generates iPSCderived cells with hepatocyte characteristics (http:// www.stembook.org/node/721) [14]. The differentiation process was observed by following the expression of markers that reflect specific stages of hepatocyte differentiation by immunocytochemistry. Figure 2 shows that prior to the initiation of differentiation the cells expressed proteins associated with pluripotency including OCT4, whereas markers expressed in differentiated cells, such as SOX17 were not detected (Figure 2, Day 0). To generate definitive endoderm, Activin A, BMP4, and FGF2 were added to the culture during the first two days of differentiation, then Activin A alone was included for a subsequent 3 days. At this stage nearly all the cells expressed FOXA2 




and SOX17, both of which are robustly expressed in the definitive endoderm (Figure 2, day 5). To generate hepatic progenitor cells, Activin A was removed from the medium and replaced with BMP4 and FGF2. After 5 days in culture nearly all of the cells expressed HNF4a, which is a transcription factor that is expressed in hepatic progenitor cells and is essential for their differentiation to hepatocytes (Figure 2, day 10) [15]. At this stage, some cells also began to express low levels of alpha-fetoprotein (AFP), which is another marker of the early hepatic lineage. After the addition of HGF for a further 5 days, which induces the hepatic progenitors to differentiate into fetal hepatocytes, the cells continued to express HNF4a and the cells increased expression of AFP, which became easily detected in nearly all of the cells in the culture (Figure 2, day 15). These fetal hepatocyte-like cells were then cultured for a further 5 days in Hepatocyte Culture Media supplemented with
Oncostatin M. By completion of the protocol, nearly all of the cells expressed Albumin (Figure 2, day 20). During the differentiation process the morphology of the cells changed to eventually adopt a cuboidal appearance, with a high cytoplasmic to nuclear ratio, and evidence of glycogen granules and lipid vesicles observed in the cytoplasm (Figure 2). We confirmed that the differentiated cells retained an aneuploid phenotype by performing karyotype analyses after the completion of the differentiation protocol. As expected, the differentiated cells exhibited a low mitotic index, and very few cells were in metaphase at the time of cell harvest. A total of four metaphase cells were recovered; however, the chromosome morphology was poor and so we were unable to perform a thorough g-band analysis. Nevertheless, the chromosomal content of these cells was polyploid and the cells appeared to have a structural abnormality tentatively associated with chromosome 17 . 


\begin{tabular}{lll}
$\begin{array}{l}\text { Table } 1 \text { Chromosomal abnormalities identified in of } \\
\text { iPSC-K3 }\end{array}$ \\
$\begin{array}{ll}\text { aneuploid } \\
\text { chlls }\end{array}$ & $\begin{array}{l}\text { Frequency (out of } \\
\mathbf{1 9} \text { cells examined) }\end{array}$ \\
\hline Chromosome & Abnormality & 19 \\
\hline$Y$ & Gain & 19 \\
3 & Loss & 18 \\
6 & Loss & 5 \\
7 & Loss & 18 \\
8 & Loss & 16 \\
11 & Loss & 19 \\
12 & Gain & 3 \\
13 & Loss & 4 \\
14 & Loss & 19 \\
15 & Loss & 12 \\
16 & Loss & 5 \\
17 & Loss & 19 \\
17 & (q11.2q25)ins(17)(q25;q25q11.2) \\
18 & Loss & 12 \\
19 & Loss & 19 \\
22 & Loss & 11 \\
\hline & & \\
\hline & & 19
\end{tabular}

To gain a better understanding of the efficiency of differentiation we used qRT-PCR to determine the relative levels of several hepatic mRNAs in primary human hepatocytes and hepatocyte-like cells derived from either control iPSC-K3 or from iPSC-K3 ${ }^{\text {aneuploid }}$ cells in independent differentiations $(\mathrm{n}=5)$. As shown in Figure 3, the levels of APOA1, APOB, CPS1, CYP1A1, FGA, FGG, GSTA1, HGD, HNF1A, HNF4A, LXR, RXR, SERPINA1, SLC10A1, TF, and TTR mRNAs could be detected in all cell types. Although significant differences $(p \leq 0.05)$ in the levels of a subset of hepatic mRNAs were observed between the different lines, the hepatocyte-like cells derived from iPSC-K3 $3^{\text {aneuploid }}$ cells exhibited an overall expression profile that was very similar to the parental cells. As we have described previously all iPSC-derived hepatocytes also retained expression of some fetal mRNAs including AFP and a number of mRNAs that are normally expressed in mature hepatocytes, including CYP3A4, were undetected in both control and iPSC$\mathrm{K} 3^{\text {aneuploid }}$ hepatocyte-like cells (data not shown).

Hepatocyte-like cells derived from aneuploid iPSCs retain functional activities associated with primary hepatocytes

The identification of proteins and mRNAs that are normally expressed during normal hepatocyte differentiation suggested that aneuploidy did not have a substantial impact on formation of hepatocytes from iPSCs. However, we recognized that this was a limited set of markers and so felt that it was important to determine whether the differentiated cells displayed activities that are normally associated with both primary hepatocytes and hepatocyte-like cells derived from euploid iPSCs $[14,13]$. The ability to store glycogen was assessed by Periodic Acid Schiff staining of cells (Figure 4A), oil red $\mathrm{O}$ staining revealed the presence of lipid droplets within the differentiated cells (Figure 4B), the cells were capable of the uptake of Indocyanine Green (Figure 4C), and incubation with fluorescently labeled low-density lipoprotein demonstrated the ability of the differentiated cells to uptake LDL (Figure 4D). Finally, we analyzed the supernatant in which the differentiated cells were cultured and observed that the iPSC-K3 $3^{\text {aneuploid }}$ derived cells effeciently secreted Albumin (Figure 4E) at levels that were statistically indistinguishable from the iPSC-K3 derived cells. From these data, we conclude that the aneuploid status of the iPSC-K3 cells does not hinder their ability to differentiate into hepatocyte-like cells.

\section{Discussion}

In the current study we have shown that cells with hepatocyte characteristics can be generated from iPSCs that harbor a severely abnormal chromosomal state. Although from a developmental perspective the successful directed differentiation of aneuploid iPSCs may seem surprising, the cells used in the current study retained representative loci from all chromosomes, albeit in an unbalanced state. It is likely that as regulatory networks are established during differentiation they stabilize through cross-regulation and so chromosomal imbalances may have little impact when cells are differentiated in culture. The iPSC-K $3^{\text {aneuploid }}$ line also has a heterogeneous karyotype and the observed chromosomal abnormalities likely reflect the selective pressure of the culture environment. If a specific chromosomal arrangement were detrimental to cell viability or proliferation it would be lost during the culture of the pluripotent cells and if it were detrimental for hepatocyte formation it potentially could be selected against during the 20-day differentiation process.

Although in general it would be deemed prudent to ensure pluripotent stem cells retain a normal karyotype, it is possible that for some applications aneuploid cells could offer advantages. Indeed cancer cells with abnormal karyotypes have been used extensively for the study of cell function and activity because they can be easily grown in culture. Since iPSCs with abnormal karyotypes often grow robustly in culture they could be useful for applications that require large numbers of cells, such as drug screening and biochemical applications, especially if sub-lines can be identified that differentiate particularly well as a consequence of the chromosomal environment. In addition, comparative analyses between parental cells and aneuploid derivatives may be useful for the identification of loci that confer specific functional phenotypes, 




especially as they relate to cell growth. In the case of hepatocytes this may be particularly relevant given the variation in ploidy that is observed in adult hepatocytes and the potential contribution of ploidy to hepatocyte function.

\section{Conclusions}

To conclude we have demonstrated that a human iPSC line that has extensive chromosomal abnormalities retains the ability to differentiate into cells that display hepatocyte characteristics. These data demonstrate that there exists considerable flexibility in the chromosomal content that is compatible with differentiation of pluripotent cells to the hepatocyte lineage.

\section{Methods}

\section{Cell culture}

Human iPSCs (iPSC-K3 [13]) were routinely cultured under low oxygen conditions $\left(4 \% \mathrm{O}_{2} / 5 \% \mathrm{CO}_{2}\right)$ in hES cell media (DMEM/F12 medium supplemented with 20\% knockout serum replacement (Invitrogen), non essential amino acids (Invitrogen), glutamine (Invitrogen), penicillin/streptomycin (Invitrogen) and zbFGF $(4 \mathrm{ng} / \mathrm{ml})$ ) on mitotically inactivated mouse embryonic fibroblasts (MEFs). Alternatively, cells were cultured on a recombinant E-cadherin-IgG Fc fusion protein matrix [16] (StemAdhere, Primorigen Biosciences, Inc) in MEF-conditioned hES medium or mTeSR [17]. When cultured on E-cadherin-IgG Fc, cells were passaged every 4-5 days by non-enzymatic methods using Versene/EDTA. All work carried out using human pluripotent stem cells was approved by the MCW Human Stem Cell Research Oversight Committee (hSCRO approval\# 09-005) and all work performed using animals was approved by the MCW IACUC.

\section{Hepatocyte-like cell differentiation}

Pluripotent cells were differentiated as discussed previously $[14,18]$. Briefly, pluripotent cells cultured on E-cadherinIgG Fc were harvested using Accutase (Millipore) and 


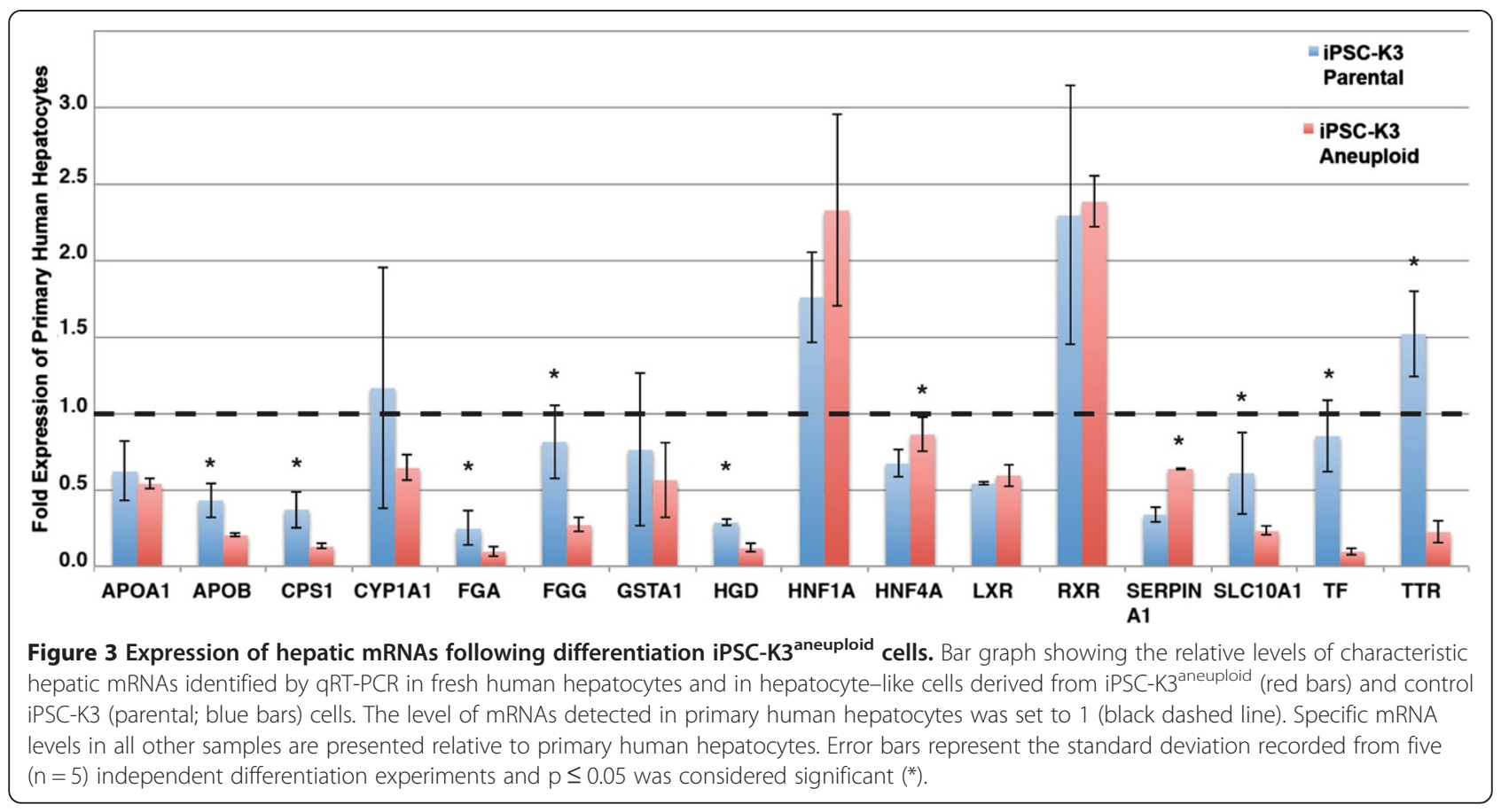

plated onto 6-well tissue culture-treated plates pre-coated with $2 \mathrm{mg} / \mathrm{ml}$ Matrigel (Geltrex; Invitrogen). Typically, one $100 \mathrm{~mm}$ dish of cells cultured on E-cadherin-IgG Fc provided enough cells for 2 wells of a 6-well plate. Approximately 24 hours after seeding the cells onto Matrigel, when the cells were $85-95 \%$ confluent, differentiation was initiated by culture for 5 days with $50 \mathrm{ng} / \mathrm{ml}$ Activin A (R\&D Systems) in RPMI/B27 (without Insulin) supplement (Invitrogen) under ambient oxygen $/ 5 \% \mathrm{CO}_{2}$. In addition, we included $10 \mathrm{ng} / \mathrm{ml} \mathrm{BMP4}$ (Peprotech) and $20 \mathrm{ng} / \mathrm{ml} \mathrm{FGF-2} \mathrm{(Invitrogen)} \mathrm{for} \mathrm{the} \mathrm{first} 2$ days. This resulted in reproducible differentiation into definitive endoderm at efficiencies of greater than $80 \%$. Cells were cultured for 5 days with $20 \mathrm{ng} / \mathrm{ml} \mathrm{BMP4}$ (Peprotech)/ $10 \mathrm{ng} / \mathrm{ml}$ FGF-2 (Invitrogen) in RPMI/B27 (containing Insulin) under $4 \% \mathrm{O}_{2} / 5 \% \mathrm{CO}_{2}$, then 5 days with $20 \mathrm{ng} / \mathrm{ml}$ HGF (Peprotech) in RPMI/B27 (containing Insulin) under $4 \% \mathrm{O}_{2} / 5 \% \mathrm{CO}_{2}$, and finally for 5 days with $20 \mathrm{ng} / \mathrm{ml}$ Oncostatin-M (R\&D Systems) in Hepatocyte Culture Media (Lonza) supplemented with SingleQuots (without EGF) in ambient oxygen $/ 5 \% \mathrm{CO}_{2}$.

\section{Karyotype analysis}

Pluripotent cells were cultured in T25 flasks coated with Matrigel in MEF-conditioned media for 2-3 days. Cells were transported to WiCell Research Institute (Madison, WI), who performed cell harvest and karyotype analysis of metaphase chromosomes using G-banding. For karyotype analysis of iPS cell-derived hepatocytes, cells were differentiated on 6-well tissue culture dishes coated with
Matrigel. After three days of culture in Hepatocyte Culture Medium and Oncostatin $M$, cells were sent to WiCell Research Institute (Madision, WI) for cell harvest and analysis.

\section{Quantitative real-time PCR analysis}

Total RNA was collected from cells at each stage of the differentiation using the RNeasy Mini Kit (Qiagen). Contaminating genomic DNA was removed using $1 \mu \mathrm{l}$ of RNase-free DNaseI per $5 \mu \mathrm{g}$ RNA. First strand cDNA was synthesized using MMLV-RT with dNTPs and random hexamer primers. Taqman-based qRT-PCR assays (PrimeTime) were obtained from IDT (Table 2) and PCR performed using an Applied Biosystems StepOnePlus ${ }^{\text {th }}$ Real-Time PCR System. All data were collected from reactions performed in triplicate.

\section{Enzyme linked immunosorbent assay}

Concentration of human albumin in cell culture supernatant was measured using the Human Albumin ELISA Quantitation Set (Bethyl; E80-129) according to the manufacturer's instructions. Absorbance (OD) was read on a plate reader within 15 minutes at $450 \mathrm{~nm}$. Raw values were converted to concentration based on the standard curve for each experimental run using ReaderFit (http://www. readerfit.com).

\section{Periodic acid Schiff staining}

For glycogen detection, differentiated cells were fume-fixed by adding $1 \mathrm{ml}$ PBS with calcium and magnesium to each 


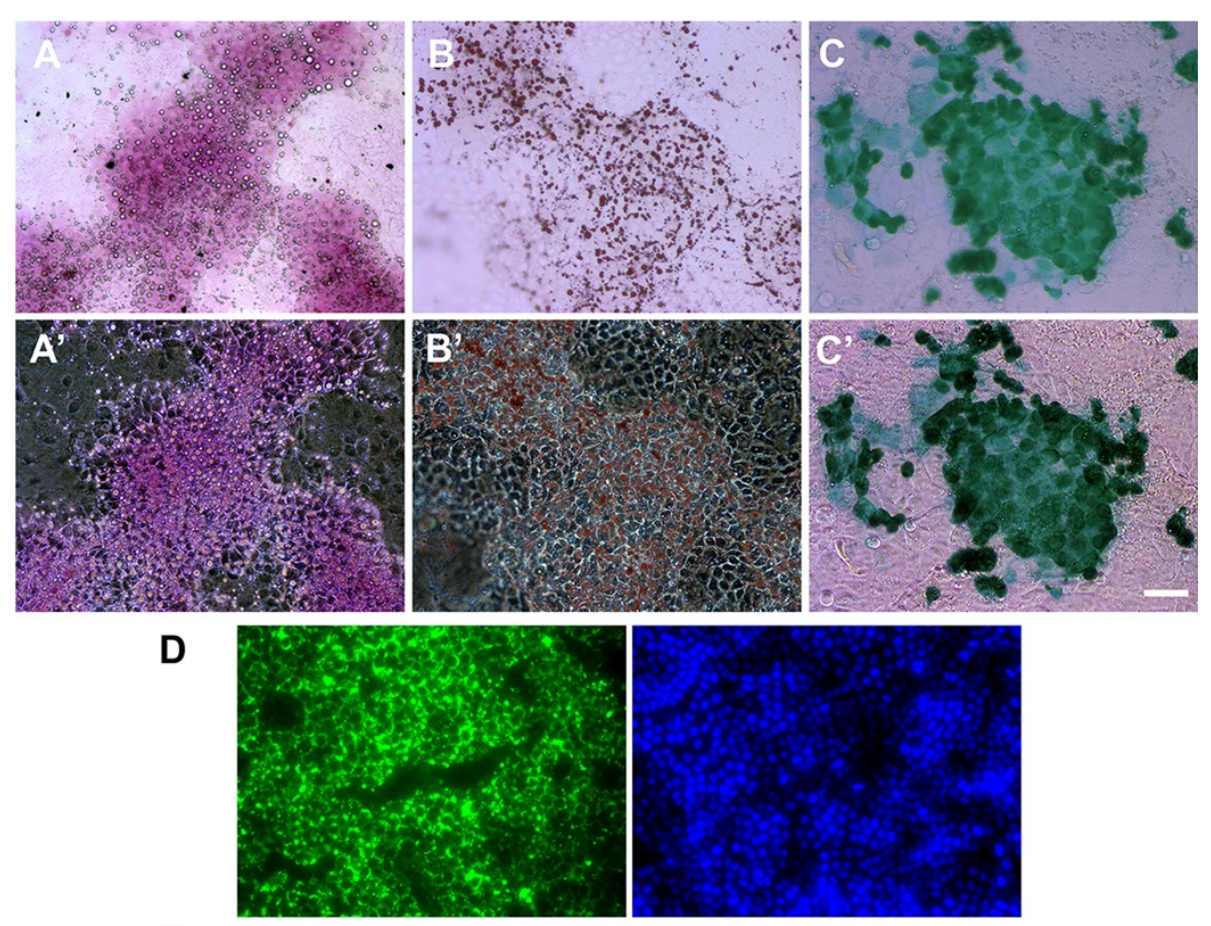

E

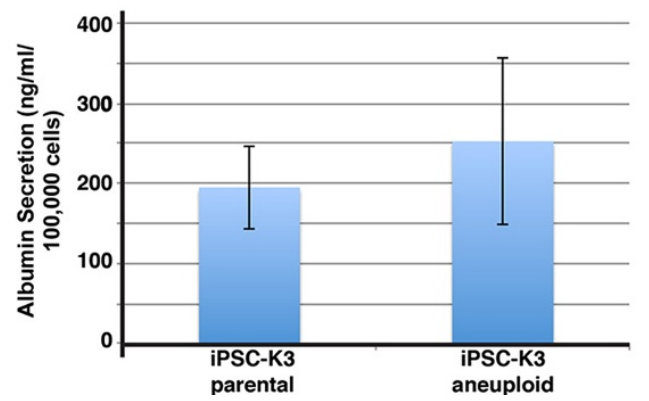

Figure 4 Identification of basic hepatocyte functions in cells derived from iPSC-K3 ${ }^{\text {aneuploid }}$ cells. Top panels show bright-field images with their corresponding phase contrast images below; scale bar $=100 \mu \mathrm{m}$. (A, A') iPSC-K3 derived hepatocytes are capable of storing glycogen as shown by periodic acid-Schiff staining. (B, $\left.\mathbf{B}^{\prime}\right)$ Oil Red O staining demonstrates the cells' ability to store lipids. (C, $\left.\mathbf{C}^{\prime}\right)$ Cells can take up indocyanine green. D) Differentiated cells were incubated with fluoresceinated low-density lipoprotein to demonstrate their ability to internalize LDL. The corresponding DAPI image is seen in the right panel. E) Bar graph showing levels, measured by ELISA, of human Albumin secreted into the culture medium from hepatocyte-like cells derived from either parental iPSC-K3 or iPSC-K3 ${ }^{\text {aneuploid }}$ cells. Error bars represent the standard deviation recorded from three $(n=3)$ independent differentiations and no statistically significant difference in Albumin levels $(p=0.45)$ was observed.

well and $4 \%$ paraformaldehyde in the spaces between the wells. Fixation occurred by incubation at $37^{\circ} \mathrm{C}$ for 1 hour. Cells were permeabilized with $0.4 \%$ Triton X-100 in PBS for 20 minutes at room temperature. Control cells were incubated with Diastase ( $1 \mathrm{mg} / \mathrm{ml}$ in PBS; Sigma) for 1 hour $37^{\circ} \mathrm{C}$. Cells were then incubated with Periodic acid $(0.5 \mathrm{~g}$ dissolved in $100 \mathrm{ml}$ nano-pure water) for $5 \mathrm{~min}$ at room temperature, washed with distilled water and incubated with fresh prepared Schiff's reagent for $15 \mathrm{~min}$.

\section{Low-density lipoprotein (LDL) uptake}

LDL uptake assays were performed as previously described [19], based on published protocols [20,21]. At the end of the differentiation protocol, cells were washed 3 times with ice-cold PBS, then incubated in ice-cold Hepatocyte Culture Media containing $5 \mu \mathrm{g} / \mathrm{ml}$ BODIPY $^{\oplus}$ FL LDL (Invitrogen) for 3.5 hours at $37^{\circ} \mathrm{C}$. Unbound $\mathrm{LDL}$ was rinsed away with $5 \mathrm{mg} / \mathrm{ml}$ heparin in PBS before imaging.

\section{Indocyanine green uptake}

Cellular uptake of indocyanine green (Cardiogreen; Sigma) was performed using indocyanine green at $1 \mathrm{mg} / \mathrm{ml}$ diluted in Hepatocyte Culture Medium (stock is $5 \mathrm{mg} / \mathrm{ml} \mathrm{reconsti-}$ tuted in water, stable for up to 8 hours). Differentiated cells were incubated for 1 hour at $37^{\circ} \mathrm{C}$ and rinsed three times with PBS before imaging. 
Table 2 Primers used in real-time qRT-PCR assays

\begin{tabular}{|c|c|c|c|}
\hline & Probe & Primer 1 & Primer 2 \\
\hline APOA1 & CTGCCAGAAATGCCGAGCCTG & CTITGAGCACATCCACGTACA & GCCGTGCTCTTCCTGAC \\
\hline APOB & CTGGATACCGTGTATGGAAACTGCTCC & CATTGCCCTTCCTCGTCTT & CCAGAGACAGAAGAAGCCAAG \\
\hline CPS1 & TCCAGCAATCATTCCGGCCAAGA & CCACAGGATTTAAGATACCCCAG & GTAATTGTTCAGCCACACCAAG \\
\hline CYP1A1 & TCTGTGATGTCCCGGATGTGGC & CCCAACCCTTCCCTGAATG & TTCTTCTCCTGACAGTGCTCAATC \\
\hline FGA & CAGGCAGACGATCCTCATGGAAAACA & CAGCCCCACCCTTAGAAAAG & CTCCTTCAGCTAGAAAGTCACC \\
\hline FGG & AATAAGGGAGCTAAACAGAGCGGGC & CAAAGACACGGTGCAAATCC & TTCCAGACCCATCGATTTCAC \\
\hline GSTA1 & CGGGCTGACATTCATCTGGTGGA & AAATCGCTACTTCCCTGCC & GGAAGCTGGAGATAAGACTGG \\
\hline HGD & ATGCAGGCCACTCACAAAGTCTACTT & AGCAAGCCATTGTTAGACTT & CCTGATCCTAACCAGCTTAGATG \\
\hline HNF1A & CAGGTTGGTGGTGTCGGTGATGA & GCCCTCTACAGCCACAAG & CAGTGTCTGAGGTGAAGACC \\
\hline HNF4A & CAAGAAATGCTTCCGGGCTGGC & ATAGCTTGACCTTCGAGTGC & TGGACAAAGACAAGAGGAACC \\
\hline LXR & TGCATAGCTCGTTCCCCAGCATTT & CCCTTCAGAACCCACAGAG & CGCAGCTCAGAACATTGTAGT \\
\hline RPL13A & AGCAGTACCTGTTTAGCCACGATGG & GCCTTCACAGCGTACGA & CGAAGATGGCGGAGGTG \\
\hline RXR & AGTACTGCCGCTACCAGAAGTGC & AGGACTGCCTGATTGACAAG & GACTCCACCTCATTCTCGTTC \\
\hline SERPINA1 & TGGTGCCTGAAGCTGAGGAGAC & AGCCAGGGAGACAGGGA & CTTAAATACGGACGAGGACAGG \\
\hline SLC10A1 & AACCTCAGCATTGTGATGACCACCT & TGTACAGGAGGAGAGGCATC & ACCTGTCCAATGTCTTCAGTC \\
\hline TF & CTGTGTCAACTGTGTCCAGGGTGT & TGAGCCACGTAAACCTCTTG & AGTATTGGTTAAGGGTGGAGC \\
\hline TTR & AGCAGCCTAGCTCAGGAGAAGTGA & CAGGTTGGAGTCAGATTGG & CCATCCTGCCAAGAATGAGT \\
\hline
\end{tabular}

\section{Oil red $\mathrm{O}$ staining}

For the detection of lipid accumulation, differentiated cells were fixed with $4 \%$ paraformaldehyde in PBS for 20 minutes at room temperature, washed twice with nano-pure water for 5 minutes, then washed with $60 \%$ 2 -propanol for 5 minutes. Cells were then incubated for $20 \mathrm{~min}$ at room temperature with a freshly prepared working solution. A $0.5 \%$ stock solution of Oil Red O was prepared by dissolving $0.05 \mathrm{~g}$ in $100 \mathrm{ml}$ 2-propanol and incubating at room temperature overnight. The working solution contained 60\% Oil Red O stock solution and $40 \%$ water, which was allowed to stand for 20 minutes at room temperature and then passed through a $0.20 \mu \mathrm{m}$ filter before using. Cell nuclei were then counterstained with hematoxylin.

\section{Immunocytochemistry of cultured cells}

Cultured cells were fixed with $4 \%$ paraformaldehyde for $20 \mathrm{~min}$ at room temperature, made permeable with $0.4 \%$ Triton X-100 in PBS for 15 min and blocked with 3\% BSA in PBS for 1 hour. Cells were incubated overnight at $4^{\circ} \mathrm{C}$ with primary antibodies diluted in $1 \%$ BSA in PBS. Primary antibodies used were Oct3/4 (Santa Cruz; rabbit, 1:500), Sox17 (R\&D Systems; goat, 1:250), FoxA2 (Novus Biologicals; Mouse, 1:1000), HNF4a (Santa Cruz; goat, 1:250), AFP (Sigma; mouse, 1:1000), and Albumin (DAKO; rabbit, 1:500). Primary antibodies were probed with respective secondary antibodies conjugated to Alexa Fluor 488 or 594 (Molecular Probes; 1:1000) and nuclei were visualized with DAPI.

\section{Flow cytometry analysis}

Pluripotent iPS cells grown on E-cadherin-IgG Fc were removed from the plate by incubating with Accutase (Millipore) for 3 minutes at room temperature. Cells were blocked with 10\% FBS (Gibco) in 1XPBS on ice for 15 minutes, then labeled with antibodies conjugated to fluorophores diluted 1:20 in 1\% FBS (100 $\mu$ l total) on ice for 20 minutes. Cells were washed with $1 \%$ FBS and resuspended in 1\% FBS for analysis. Antibodies used were mouse anti-human CD13-488 (AbD Serotec), mouse anti-human SSEA-4-PE (Millipore FlowCellect), and mouse anti-human Tra-1-81-PE (Millipore FlowCellect). Unstained cells and cells stained with the appropriate fluorophore-conjugated isotype were used as controls.

\section{Abbreviations \\ iPSC: Induced pluripotent stem cell; ESC: Embryonic stem cell: FACS: Fluorescent activated cell sorting; LDL: Low density lipoprotein.}

\section{Competing interests}

The authors declare that they have no competing interests.

\section{Authors' contributions}

FKN: Contributed to experimental design, performed the majority of experiments and wrote draft of manuscript. MRD: Performed cell differentiations, GRT-PCR analyses, contributed to FACS studies and generated figures. JC: Contributed to qRT-PCR experiments. MAC: Performed LDL uptake assays. SKM: Performed albumin ELISAs. SAD: Contributed to experimental design, oversight of experiments performed, data interpretation, and wrote final version of manuscript. All authors read and approved the final manuscript.

\section{Acknowledgements}

This work was supported by gifts from the Marcus Family, the Phoebe R. and John D. Lewis Foundation, the Sophia Wolf Quadracci Memorial Fund, the Dr. James Guhl Memorial Fund, the Advancing a Healthier Wisconsin Fund, 
and by NIH grants DK55743, HG006398 and HL094857 (to SAD), DK091994 (to MAC), AA019874 (to FKN), DK098926 (to MRD) and a JDRF Fellowship 3-2010-497 (to JC).

Received: 12 November 2013 Accepted: 30 June 2014

Published: 8 July 2014

\section{References}

1. Robinton DA, Daley GQ: The promise of induced pluripotent stem cells in research and therapy. Nature 2012, 481:295-305.

2. Takahashi K, Tanabe K, Ohnuki M, Narita M, Ichisaka T, Tomoda K, Yamanaka S: Induction of pluripotent stem cells from adult human fibroblasts by defined factors. Cell 2007, 131:861-872

3. Yu J, Vodyanik MA, Smuga-Otto K, Antosiewicz-Bourget J, Frane JL, Tian S, Nie J, Jonsdottir GA, Ruotti V, Stewart R, Slukvin II, Thomson JA: Induced pluripotent stem cell lines derived from human somatic cells. Science 2007, 318:1917-1920.

4. Ronen D, Benvenisty N: Genomic stability in reprogramming. Curr Opin Genet Dev 2012, 22:444-449.

5. Taapken SM, Nisler BS, Newton MA, Sampsell-Barron TL, Leonhard KA, McIntire EM, Montgomery KD: Karotypic abnormalities in human induced pluripotent stem cells and embryonic stem cells. Nat Biotechnol 2011, 29:313-314.

6. Pasi CE, Dereli-Oz A, Negrini S, Friedli M, Fragola G, Lombardo A, Van Houwe G, Naldini L, Casola S, Testa G, Trono D, Pelicci PG, Halazonetis TD: Genomic instability in induced stem cells. Cell Death Differ 2011, 18:745-753.

7. Martins-Taylor K, Nisler BS, Taapken SM, Compton T, Crandall L, Montgomery KD, Lalande $\mathrm{M}, \mathrm{Xu} \mathrm{RH}$ : Recurrent copy number variations in human induced pluripotent stem cells. Nat Biotechnol 2011, 29(6):488-491.

8. Mayshar Y, Ben-David U, Lavon N, Biancotti JC, Yakir B, Clark AT, Plath K, Lowry WE, Benvenisty N: Identification and classification of chromosomal aberrations in human induced pluripotent stem cells. Cell Stem Cell 2010, 7:521-531.

9. Gore A, Li Z, Fung HL, Young JE, Agarwal S, Antosiewicz-Bourget J, Canto I, Giorgetti A, Israel MA, Kiskinis E, Lee JH, Loh YH, Manos PD, Montserrat N, Panopoulos AD, Ruiz S, Wilbert ML, Yu J, Kirkness EF, Izpisua Belmonte JC, Rossi DJ, Thomson JA, Eggan K, Daley GQ, Goldstein LS, Zhang K: Somatic coding mutations in human induced pluripotent stem cells. Nature 2011, 471:63-67.

10. Laurent LC, Ulitsky I, Slavin I, Tran H, Schork A, Morey R, Lynch C, Harness JV, Lee S, Barrero MJ, Ku S, Martynova M, Semechkin R, Galat V, Gottesfeld J, Izpisua Belmonte JC, Murry C, Keirstead HS, Park HS, Schmidt U, Laslett AL, Muller FJ, Nievergelt CM, Shamir R, Loring JF: Dynamic changes in the copy number of pluripotency and cell proliferation genes in human ESCs and iPSCs during reprogramming and time in culture. Cell Stem Cell 2011, 8:106-118.

11. Duncan AW, Taylor MH, Hickey RD, Hanlon Newell AE, Lenzi ML, Olson SB, Finegold MJ, Grompe M: The ploidy conveyor of mature hepatocytes as a source of genetic variation. Nature 2010, 467:707-710.

12. Duncan AW, Hanlon Newell AE, Smith L, Wilson EM, Olson SB, Thayer MJ, Strom SC, Grompe M: Frequent aneuploidy among normal human hepatocytes. Gastroenterology 2012, 142:25-28.

13. Si-Tayeb K, Noto FK, Sepac A, Sedlic F, Bosnjak ZJ, Lough JW, Duncan SA: Generation of human induced pluripotent stem cells by simple transient transfection of plasmid DNA encoding reprogramming factors. BMC Dev Biol 2010, 10:81.

14. Si-Tayeb K, Noto FK, Nagaoka M, Li J, Battle MA, Duris C, North PE, Dalton S, Duncan SA: Highly efficient generation of human hepatocyte-like cells from induced pluripotent stem cells. Hepatology 2010, 51:297-305.

15. Delaforest A, Nagaoka M, Si-Tayeb K, Noto FK, Konopka G, Battle MA, Duncan SA: HNF4A is essential for specification of hepatic progenitors from human pluripotent stem cells. Development 2011, 138:4143-4153.

16. Nagaoka M, Si-Tayeb K, Akaike T, Duncan SA: Culture of human pluripotent stem cells using completely defined conditions on a recombinant E-cadherin substratum. BMC Dev Biol 2010, 10:60

17. Ludwig TE, Bergendahl V, Levenstein ME, Yu J, Probasco MD, Thomson JA: Feeder-independent culture of human embryonic stem cells. Nat Methods 2006, 3:637-646.

18. Mallanna SK, Duncan SA: Differentiation of hepatocytes from pluripotent stem cells. Curr Protoc Stem Cell Biol 2013, 26:Unit 1G.4.
19. Cayo MA, Cai J, DeLaForest A, Noto FK, Nagaoka M, Clark BS, Collery RF, Si-Tayeb K, Duncan SA: JD induced pluripotent stem cell-derived hepatocytes faithfully recapitulate the pathophysiology of familial hypercholesterolemia. Hepatology 2012, 56:2163-2171.

20. Harwood HJJ, Pellarin LD: Kinetics of low-density lipoprotein receptor activity in Hep-G2 cells: derivation and validation of a Briggs-Haldane-based kinetic model for evaluating receptor-mediated endocytotic processes in which receptors recycle. Biochem J 1997, 323:649-659.

21. Jackson KG, Maitin V, Leake DS, Yaqoob P, Williams CM: Saturated fat-induced changes in Sf 60-400 particle composition reduces uptake of LDL by HepG2 cells. J Lipid Res 2006, 47:393-403.

doi:10.1186/1756-0500-7-437

Cite this article as: Noto et al:: Aneuploidy is permissive for hepatocytelike cell differentiation from human induced pluripotent stem cells. $B M C$ Research Notes 2014 7:437.

\section{Submit your next manuscript to BioMed Central and take full advantage of:}

- Convenient online submission

- Thorough peer review

- No space constraints or color figure charges

- Immediate publication on acceptance

- Inclusion in PubMed, CAS, Scopus and Google Scholar

- Research which is freely available for redistribution

Submit your manuscript at www.biomedcentral.com/submit
C Biomed Central 